\title{
A novel exocrine structure of the bicellular unit type in the thorax of termites
}

\author{
Teresa Telles Gonçalves ${ }^{1}$, Og DeSouza ${ }^{1}$ and Johan Billen ${ }^{2}$
}

\author{
${ }^{1}$ Universidade Federal de Viçosa, \\ Departamento de Biologia Animal, \\ 36.570-000 Viçosa, MG, Brazil; ${ }^{2}$ Zoological \\ Institute, University of Leuven, \\ Naamsestraat 59, box 2466, B-3000 \\ Leuven, Belgium
}

\section{Keywords:}

Exocrine glands, Cornitermes, Microcerotermes, Nasutitermes, ultrastructure

Accepted for publication:

1 December 2008

\begin{abstract}
Gonçalves, T. T., DeSouza, O. and Billen, J. 2010. A novel exocrine structure of the bicellular unit type in the thorax of termites - Acta Zoologica (Stockholm) 91: $193-198$
\end{abstract}

Studying the thorax of some Termitidae species, we found two pairs of hitherto unknown lateral glands in the mesothorax and metathorax of both workers and soldiers. The glands consist of distinct clusters of class 3 secretory cells accompanied by their duct cells, located in the upper lateral portion of the thoracic wall. Ultrastructural observations reveal numerous mitochondria, a well-developed Golgi apparatus and vesicular smooth endoplasmic reticulum, indicating a cytoplasm with intensive metabolic activity. The gland is reported to occur in Microcerotermes strunckii, Cornitermes cumulans and Nasutitermes minor, three species comprising an interesting morpho-behavioural gradient, respectively, from only mechanical, through mechanical-chemical, to only chemical defence systems. The extent of such a gradient allows speculations that this gland would be related to the general needs of termites, rather than to some specificities of a single group. We warn, however, that complementary studies are needed, before any conclusions can be drawn.

J. Billen, Zoological Institute, Naamsestraat 59, box 2466, B-3000 Leuven, Belgium. E-mail: Johan.Billen@bio.kuleuven.be

\section{Introduction}

The fascinating life of social insects has long attracted human attention. One of the characteristics of these insects is the amazing development of their exocrine system, the secretions of which play an essential role in many aspects of social life (Billen 2006). Among the social insects, however, it is surprising to see the relatively limited number of exocrine glands that have been described in termites, compared with the considerably higher variety of the exocrine system in the social Hymenoptera. Termites can have a total of 17 glands (Table 1), while approximately 70 glands form the overall exocrine repertoire of ants. A possible reason for this may be found in differences in the communication system between both groups: social Hymenoptera rely to a very considerable extent on pheromonal substances [and hence possess the glandular equipment for producing these (Billen and Morgan 1998)], whereas in termites acoustic signals can play an important role (Kirchner et al. 1994; Röhrig et al. 1999; Evans et al. 2007). The lower number of exocrine glands in the termites is definitely not the result of a lack of attention, as several termitologists have produced extensive and thorough studies on the isopteran exocrine apparatus (e.g. Pasteels 1965; Noirot 1969; Noirot and Quennedey 1974, 1991; Deligne et al. 1981; Leis and Sbrenna 1983; Sbrenna and Leis 1983; Quennedey 1984, 1998; Costa Leonardo and De Salvo 1987; Costa Leonardo 1994, 2004; Soares and Costa-Leonardo 2002; Sobotnik et al. 2003; Quennedey et al. 2004, 2008). As a result, finding novel glands in termites does not happen often. Studying the thorax of some Termitidae species, however, we found two pairs of hitherto unknown lateral glands in the mesothorax and metathorax of both workers and soldiers, that we here describe as a 17th exocrine structure of termites.

\section{Materials and Methods}

The termite species investigated here are Cornitermes cumulans (Kollar), Microcerotermes strunckii (Sörensen) and Nasutitermes minor (Holmgren). The M. strunckii specimens were collected in Sete Lagoas, MG, Brazil; C. cumulans and N. minor specimens were collected in Viçosa, MG, Brazil. 
Table 1 Survey of the known exocrine glands of termites, listed from head to abdomen, with indication of the cellular organization according to the classification of Noirot and Quennedey (1974), and corresponding references. For the dehiscent gland, no precise information about its class allocation is available

\begin{tabular}{llll}
\hline & Gland & Class & References \\
\hline 1 & Epidermal tegumental glands & 1 & Sobotnik et al., 2003 \\
2 & Bicellular unit tegumental glands & 3 & Leis and Sbrenna, 1983; Sbrenna and Leis, 1983; Sobotnik et al., 2003 \\
3 & Frontal gland & 1,3 & Noirot, 1969; Deligne et al., 1981; Costa Leonardo and De Salvo, 1987 \\
4 & Labral gland & 3 & Mao and Henderson, 2006 \\
5 & Cibarial gland & 1 & Quennedey, 1984 \\
6 & Mandibular base gland & 3 & Quennedey, 1984 \\
7 & Mandibular gland & 3 & Noirot, 1969 \\
8 & Labial (salivary) gland & 1 & Pasteels, 1965; Noirot, 1969 \\
9 & Tarsomere glands & 3 & Bacchus, 1979; Soares and Costa-Leonardo, 2002 \\
10 & Tibial gland & 3 & Bacchus, 1979; Soares and Costa-Leonardo, 2002 \\
11 & Lateral thoracic glands & 3 & this article \\
12 & Dehiscent gland & $?$ & Costa-Leonardo, 2004 \\
13 & Tergal glands & $1,2,3$ & Noirot, 1969; Wall, 1969; Quennedey, 1975; Ampion and Quennedey, 1981; Bordereau et al., 2002 \\
14 & Sternal glands & $1,2,3$ & Pasteels, 1965; Noirot, 1969; Quennedey, 1975; Quennedey et al., 2008 \\
15 & Posterior sternal glands & 3 & Quennedey et al., 2004, 2008 \\
16 & Spermathecal gland & 3 & Costa Leonardo and Patricio, 2005; Raina et al., 2007 \\
17 & Pleural abdominal glands & 3 & Ampion, 1980 \\
\hline
\end{tabular}

Head-thorax and thorax portions of worker specimens of the three species were fixed in cold $2 \%$ glutaraldehyde, buffered at pH 7.3 with $50 \mathrm{~mm}$ sodium cacodylate and $150 \mathrm{~mm}$ saccharose. Also, the thorax of M. strunckii and N. minor soldiers was studied. Post-fixation was performed in $2 \%$ osmium tetroxide in the same buffer, followed by dehydration in a graded acetone series. Tissues were embedded in Araldite and sectioned with a Reichert OmU2 microtome. Semi-thin sections of $1 \mu \mathrm{m}$ were stained with methylene blue and thionin and viewed in an Olympus BX-51 microscope. Double-stained thin sections of $70 \mathrm{~nm}$ thickness were examined in a Zeiss EM900 electron microscope. Workers and soldiers of $M$. strunckii were also prepared for scanning electron microscopy, the individuals were critical-point dried using a CPD 030 instrument. The dried samples were mounted on aluminium stubs using Leit- $C$ and coated with gold with a SPI-ModuleTM Sputter Coater. Images were obtained with a Jeol JSM-6360.

\section{Results}

Semi-thin transverse sections through the thorax of both workers and soldiers of $M$. strunckii and $N$. minor and of C. cumulans workers show an obvious paired glandular structure, located in the upper lateral portion of both the mesothorax and metathorax, just below the mesonotum and metanotum, respectively (Fig. 1A).

Each of these four novel lateral thoracic glands consists of a distinct cluster with an estimated number of approx. 100 glandular units. Among the studied species, the size of the gland varies in the mesothorax and metathorax. The thickness in the mesothorax varies from 15 to $40 \mu \mathrm{m}$ for
M. strunckii, it measures approx. $20 \mu \mathrm{m}$ in $N$. minor and approx. $35 \mu \mathrm{m}$ in $C$. cumulans. In the metathorax, the thickness varies from 10 to $30 \mu \mathrm{m}$ for $M$. strunckii, from 10 to $25 \mu \mathrm{m}$ for $N$. minor and is approx. $20 \mu \mathrm{m}$ for C. cumulans. The width (in dorsoventral direction) in the mesothorax ranges from 80 to $120 \mu \mathrm{m}$ for $M$. strunckii, from 35 to $60 \mu \mathrm{m}$ for $N$. minor and is approx. $80 \mu \mathrm{m}$ for $C$. cumulans. In the metathorax, the width varies from 100 to $140 \mu \mathrm{m}$ for $M$. stru$n c k i i$, from 85 to $140 \mu \mathrm{m}$ for $N$. minor and is approx. $200 \mu \mathrm{m}$ for C. cumulans. The length (in anterior/posterior direction) for $M$. strunckii ranges from 180 to $190 \mu \mathrm{m}$ in the mesothorax and from 100 to $200 \mu \mathrm{m}$ in the metathorax.

Scanning electron microscopy (Fig. 1B,C) of workers and soldiers of $M$. strunckii revealed the presence of numerous pores with a diameter of approx. $0.5 \mu \mathrm{m}$, that occur on the entire surface of the lateral region of the thorax. Most pores occur on top of a small nipple-like elevation (Fig. 1C). Additionally, scanning electron microscopy revealed the presence of hairs associated with the cuticle covering the gland region (Fig. 1C).

At the cell level, the gland is formed by bicellular units according to class 3 in the standard classification of Noirot and Quennedey (1974). A transverse section of a lateral thoracic gland shows between 5 and 10 secretory cells (Fig. 2A). They have a diameter of approx. $10 \mu \mathrm{m}$ and are characterized by rather pale and rounded nuclei with a diameter of approx. $5 \mu \mathrm{m}$. Between the secretory cells are duct cells that contain a dark and more irregularly shaped nucleus that occupies nearly the entire duct cell volume (Fig. 2A). The secretory cell contains an end apparatus with a central cuticular duct, surrounded by irregular microvilli (Fig. 2B). In the cytoplasm surrounding the end apparatus, we find 

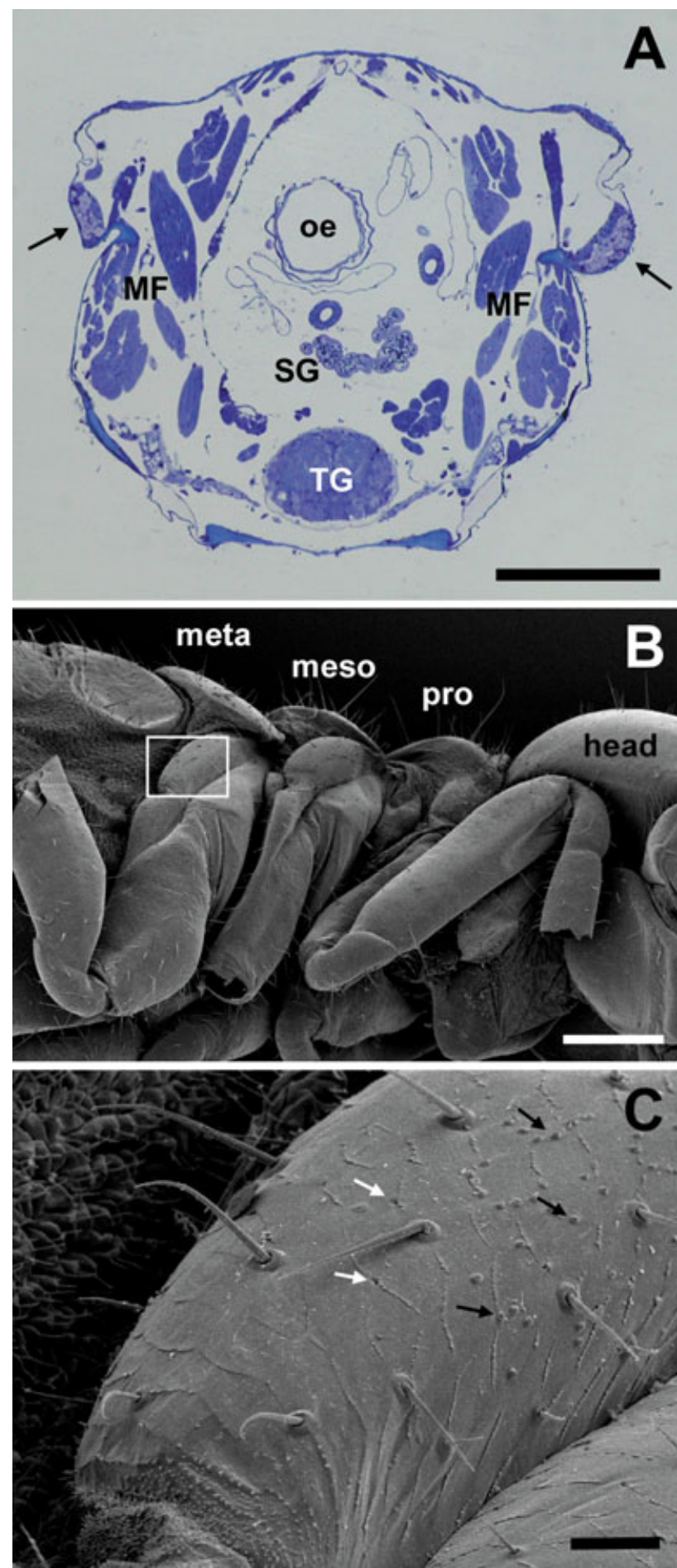

Fig. 1-A. Transverse semi-thin section through the mesothorax of a Microcerotermes strunckii worker showing the position of the lateral thoracic glands (arrows). Scale bar $100 \mu \mathrm{m}$. MF, muscle fibres; oe, oesophagus; SG, salivary gland; TG, mesothoracic ganglion.

-B. Scanning electron micrograph of the thorax of a $M$. strunckii worker, frame indicates position of lateral metathoracic gland. numerous mitochondria, a well-developed Golgi apparatus and vesicular smooth endoplasmic reticulum (Fig. 2C). The cuticular ducts have a diameter of approx. $0.5 \mu \mathrm{m}$, and generally open as pores in the centre of the nipple-like elevations through the outer thoracic tegument (Fig. 2D,E).

The basic cell arrangement of both gland pairs does not differ among the studied species, neither between workers and soldiers. However, in all species, the metathoracic cell clusters present a more linear shape when compared with the mesothoracic glandular region, which is more ellipsoid in shape.

\section{Discussion}

The paired lateral glands in the mesothorax and metathorax of the termite species studied in this article represent hitherto unknown exocrine structures for this insect group (Table 1). In 1993, Costa-Leonardo described mainly dorsally occurring oenocyte clusters in the three thoracic as well as the various abdominal segments of soldiers of C. cumulans (Costa Leonardo 1993). Their clustered appearance much resembles that of the mesothoracic and metathoracic lateral glands we describe here, but the cellular organization is different. The general structural organization of the glands now described clearly corresponds with class 3 (Noirot and Quennedey 1974), with bicellular units each comprising a secretory cell and its accompanying duct cell. Secretory cells of this class 3 display the very characteristic end apparatus (which is a cuticular continuation of the duct cell, surrounded by a microvillar sheath), but which does not occur in oenocytes. In their 1991 paper, Noirot and Quennedey updated their 1974 pioneer paper by considering the oenocytes homologous with class 2 epidermal glands (Noirot and Quennedey 1991). The oenocyte clusters reported by Costa Leonardo (1993) in C. cumulans soldiers therefore may be similar to the glands we describe, but their assignment as class 3 exocrine glands seems to have been overlooked.

If the legs are not taken into account (Billen 2009), exocrine glands in the thorax of social insects are less numerous than in the head and abdomen. The salivary (= labial) gland in the prothorax is a common structure for all social insects, while the metapleural gland in the metathorax is found only in ants (Hölldobler and Engel-Siegel 1984). In ants of the genus Diacamma, a peculiar gland occurs inside the gemmae (Peeters and Billen 1991), that appear as vestigial wing buds of the mesothorax (Baratte et al. 2006). These gemmae, however, are structurally very different from the region of the thoracic lateral glands in termites.

Scale bar $200 \mu \mathrm{m}$. - C. Scanning electron micrograph detail of $\mathrm{B}$, showing pores and hairs in the region of the metathoracic lateral gland of a M. strunckii worker. Some pores open through the flat cuticle (white arrows), but the majority open through the centre of the nipple-like elevations (black arrows).

Scale bar $20 \mu \mathrm{m}$ 


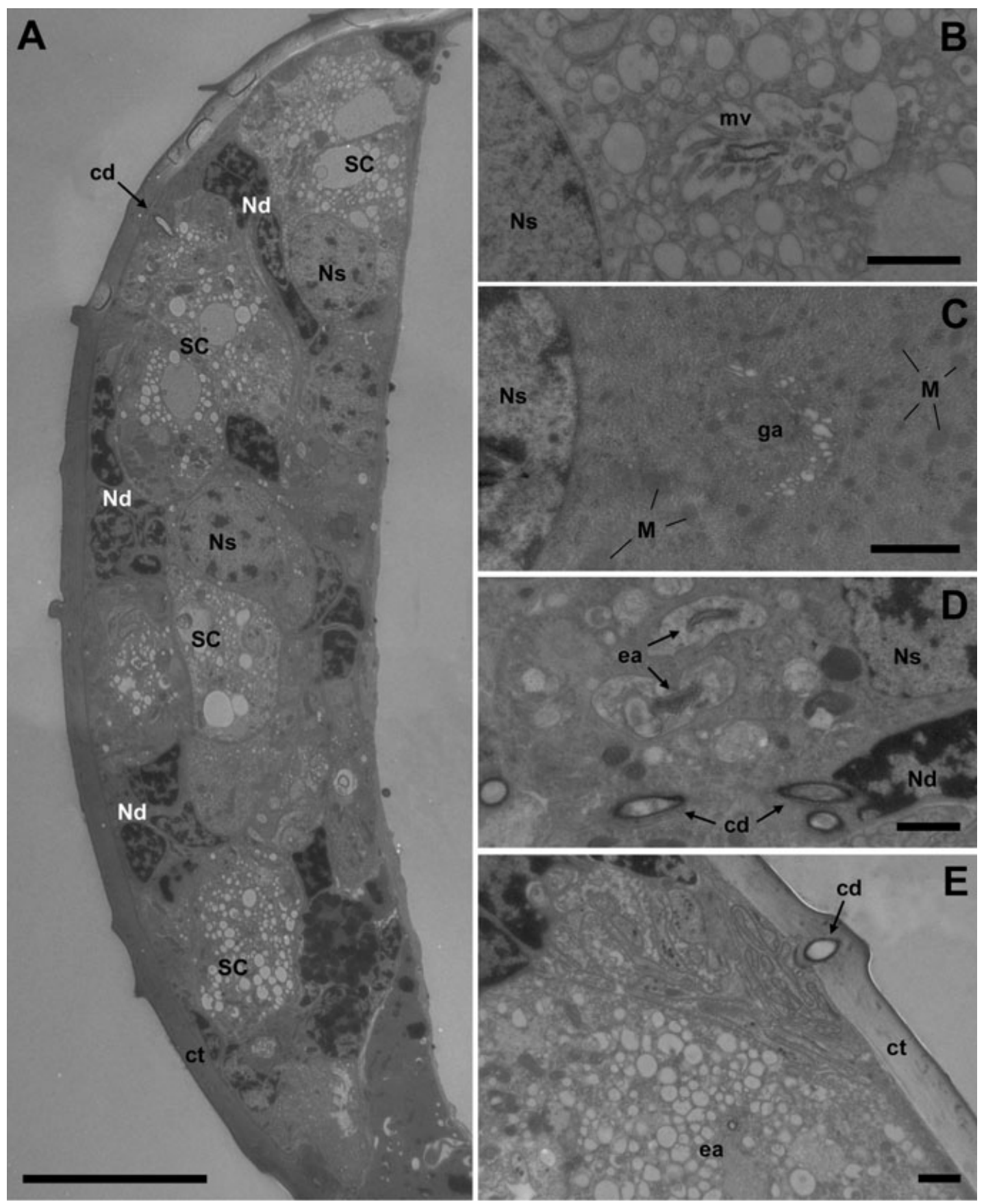

Fig. 2-A. Electron micrograph showing a transverse section through the mesothoracic lateral gland of a Microcerotermes strunckii worker, showing densely packed secretory cells (SC) and duct cells. Scale bar $10 \mu \mathrm{m}$. - B. Electron micrograph of end apparatus in mesothorax of M. strunckii soldier. Scale bar $1 \mu \mathrm{m}$. - C. Detail of cytoplasm in metathoracic gland cell of Cornitermes cumulans worker with Golgi apparatus (ga) and densely packed smooth endoplasmic reticulum. Scale bar $1 \mu \mathrm{m}$. - D. View of duct cells in metathorax of $M$. strunckii worker. Scale bar $1 \mu \mathrm{m}$.

-E. Opening of duct cell on top of nipple-like elevation through tegumental cuticle in metathorax of $M$. strunckii worker. Scale bar $1 \mu \mathrm{m}$ cd, cuticular duct; ct, cuticle; ea, end apparatus; M, mitochondria; mv, microvilli; Nd, nucleus of duct cell; Ns, nucleus of secretory cell.

Tegumental glands of the bicellular unit type (class 3 following Noirot and Quennedey 1974) with a scattered distribution over the body are known for ants (Gobin et al. 2003) and bees (Guerino et al. 2002), and have also been reported for termites (Leis and Sbrenna 1983; Sbrenna and Leis 1983). In Kalotermes flavicollis, they occur in the head, thorax and abdomen as scattered single units or in groups of two or three (Sbrenna and Leis 1983), but without a specific 
distribution pattern (Leis and Sbrenna 1983). This is in contrast with the two pairs of lateral thoracic glands that we describe here, as these represent very distinct clusters of class 3 glandular units, rather than clustered oenocytes (= class 2$)$ as reported by Costa Leonardo (1993).

The two pairs of this novel gland have the same structural appearance, and are also similar in workers and soldiers. With a well-developed smooth endoplasmic reticulum and Golgi apparatus, the general ultrastructural organization of these novel lateral thoracic glands is in line with that of the tegumental glands in Kalotermes flavicollis (Sbrenna and Leis 1983) and with the subepithelial gland in ants (Gobin et al. 2003). This cytoplasmic composition of the secretory cells is indicative for a non-proteinaceous secretion.

The function of the lateral thoracic glands remains unknown, although the non-proteinaceous nature of the secretion may correspond with a pheromonal role. Termites do not rely as extensively as ants on chemical communication. However, chemical communication in termites is essential for the maintenance of their social life (Costa Leonardo 2006), including several aspects such as nest-mate recognition (Marins and DeSouza 2008), defence (Deligne et al. 1981; Quennedey 1984), and recruitment and resource exploitation (Reinhard et al. 1997; Reinhard and Kaib 2001). The presence of hairs and sensillae associated with the cuticle in the gland region may support the theory that the secretion produced by the lateral thoracic glands is involved in chemical communication, as these also have been reported to be associated with other termite glands involved in chemical communication, such as the sternal gland (Costa Leonardo 2006).

Alternatively, the non-proteinaceous secretions from these glands could contribute to the chemical profile of the cuticular surface, and hence play an important role in nest-mate recognition. In fact, nest-mate recognition supposedly through body-to-body contact (and hence sharing cuticular hydrocarbons), has been hypothesized to be the key for the survival of grouped individuals of C. cumulans (DeSouza et al. 2001) and Nasutitermes aquilinus (Miramontes and DeSouza 1996), a species and a genus reported here to possess these thoracic glands. However, a complementary study of the thoracic glands' function is needed for any further conclusions to be drawn.

Finally, it is worth noting that such glands are reported here for genera representing two very diverse subfamilies (Termitinae and Nasutitermitinae) inside the Neotropical Termitidae. Moreover, the three genera studied here comprise an interesting morphological gradient, from only mechanical (Microcerotermes), to a mixed chemical-mechanical (Cornitermes), and finally only chemical (Nasutitermes) defence apparatus. The extent of these diverse taxonomical and morpho-behavioural realms may indicate that such a gland is widespread in termites and that it would have a function related to the general needs of termites as a whole, rather than some function specific of a single group.

\section{Acknowledgements}

We are very grateful to An Vandoren for her skilful assistance in making sections for electron microscopy and to Alex Vrijdaghs for his help in scanning electron microscopy. We are also thankful to Alessandra Marins, Daniela Faria Florencio and Nithin Mathews for all their help. T.T.G. was supported by a CAPES PhD studentship and O.D.S. by a CNPq Fellowship (no. 306 081/2007-5). This research was supported by grant G.0699.08 from the Flemish Fund for Scientific Research and CAPES/PDEE (BEX 5151/06-6). This is contribution no. 39 of the Laboratory of Termitology (http:// www.isoptera.ufv.br).

\section{References}

Ampion, M. 1980. Les glandes tergales des imagos de termites: étude comparative et signification évolutive. Phd Thesis. University of de Dijon, France.

Ampion, M. and Quennedey, A. 1981. The abdominal epidermal glands of termites and their phylogenetic significance. In Howse, P. E. and Clément, J.-L. (Eds): Biosystematics of Social Insects, pp. 249-261. Academic Press, London.

Bacchus, S. 1979. New exocrine glands on the legs of some Rhinotermitidae (Isoptera). - International fournal of Insect Morphology and Embryology 8: 135-142.

Baratte, S., Peeters, C. and Deutsch, J. S. 2006. Testing homology with morphology, development and gene expression: sex-specific thoracic appendages of the ant Diacamma. - Evolution and Development 8: 433-445.

Billen, J. 2006. Signal variety and communication in social insects. Proceedings of the Netherlands Entomological Society Meetings 17: 9-25.

Billen, J. 2009. Occurrence and structural organization of the exocrine glands in the legs of ants. - Arthropod Structure and Development 38: $2-15$.

Billen, J. and Morgan, E. D. 1998. Pheromone communication in social insects - sources and secretions. In Vander Meer, R. K., Breed, M. D., Winston, M. L. and Espelie, K. E. (Eds): Pheromone Communication in Social Insects: Ants, Wasps, Bees, and Termites, pp. 3-33. Westview Press, Boulder, Oxford.

Bordereau, C., Cancello, E. M., Sémon, E., Courrent, A. and Quennedey, A. 2002. Sex pheromone identified after solid phase microextraction from tergal glands of female alates in Cornitermes bequaerti (Isoptera, Nasutitermitinae). - Insectes Sociaux 49: 209-215.

Costa Leonardo, A. M. 1993. Occurrence and morphology of the oenocytes in soldiers of Cornitermes cumulans (Kollar) (Isoptera, Termitidae). - Revista Brasileira de Entomologia 37: 345-351.

Costa Leonardo, A. M. 1994. The leg exocrine system in Serritermes serrifer (Hagen, 1858), phylogenetic implications (Isoptera: Serritermitidae). - Insectes Sociaux 41: 111-114.

Costa-Leonardo, A. M. 2004. A new interpretation of the defense glands of neotropical Ruptitermes (Isoptera, Termitidae, Apicotermitinae). - Sociobiology 44: 391-402.

Costa Leonardo, A. M. 2006. Morphology of the sternal gland in workers of Coptotermes gestroi (Isoptera, Rhinotermitidae). - Micron 37: 551-556.

Costa Leonardo, A. M. and De Salvo, C. R. 1987. A comparative study of the frontal glands in three species of Brazilian termite soldiers (Isoptera, Termitidae). - Revista Brasileira de Entomologia 3: $465-471$. 
Costa Leonardo, A. M. and Patricio, G. B. 2005. Structure of the spermatheca in five families of Isoptera. - Sociobiology 45: 659-670.

Deligne, J., Quennedey, A. and Blum, M. S. 1981. The enemies and defense mechanisms of termites. In Hermann, H. R. (Ed.): Social Insects, Vol. 2, pp. 1-76. Academic Press, New York.

DeSouza, O., Miramontes, O., Santos, C. and Bernardo, D. 2001. Social facilitation affecting tolerance to poisoning in termites (Insecta, Isoptera). - Insectes Sociaux 48: 10-15.

Evans, T. A., Inta, R., Lai, J. C. S. and Lenz, M. 2007. Foraging vibration signals attract foragers and identify food size in the drywood termite, Cryptotermes secundus. - Insectes Sociaux 54: 374382.

Gobin, B., Ito, F. and Billen, J. 2003. The subepithelial gland in ants: a novel exocrine gland closely associated with the cuticle surface. Acta Zoologica (Stockholm) 84: 285-291.

Guerino, A. C. and de Oliveira, V. T. P. 2002. Glândulas tegumentares do abdômen. In da Cruz-Landim, C. and Abdalla, F. C. (Eds): Glândulas Exócrinas das Abelhas, pp. 111-126. Funpec Editora, Ribeirão Preto.

Hölldobler, B. and Engel-Siegel, H. 1984. On the metapleural gland of ants. - Psyche 91: 201-224.

Kirchner, W. H., Broecker, I. and Tautz, J. 1994. Vibrational alarm communication in the damp-wood termite Zootermopsis nevadensis. - Physiological Entomology 19: 187-190.

Leis, M. and Sbrenna, G. 1983. Epidermal glands and integument of different castes of Kalotermes flavicollis (Isoptera, Calotermitidae). A comparative study. - Redia 66: 215-225.

Mao, L. and Henderson, G. 2006. Ultrastructure of the head and mouthparts of Coptotermes formosanus presoldier and soldier.Sociobiology 48: 649-659.

Marins, A. and DeSouza, O. 2008. Nestmates recognition in Cormitermes cumulans termites (Insecta: Isoptera). - Sociobiology 51: 255-263.

Miramontes, O. and DeSouza, O. 1996. The nonlinear dynamics of survival and social facilitation in termites. - Fournal of Theoretical Biology 181: 373-380.

Noirot, C. 1969. Glands and secretions. In Krishna, K. and Weesner, F. M. (Eds): Biology of Termites, pp. 89-123. Academic Press, New York.

Noirot, C. and Quennedey, A. 1974. Fine structure of insect epidermal glands. - Annual Review of Entomology 19: 61-80.

Noirot, C. and Quennedey, A. 1991. Glands, gland cells, glandular units: some comments on terminology and classification. - Annales de la Société entomologique de France (N.S.) 27: 123-128.

Pasteels, J. M. 1965. Polyéthisme chez les ouvriers de Nasutitermes lujae (Termitidae Isoptères). - Biologia Gabonica 1: 191-205.

Peeters, C. and Billen, J. 1991. A novel exocrine gland inside the thoracic appendages ('gemmae') of the queenless ant Diacamma australe. - Experientia 47: 229-231.
Quennedey, A. 1975. Morphology of exocrine glands producing pheromones and defensive substances in subsocial and social insects. In Noirot, C., Howse, P. E. and Le Masne, G. (Eds): Pheromones and Defensive Secretions in Social Insects, pp. 1-21. Imprim. University of Dijon, Dijon France.

Quennedey, A. 1984. Morphology and ultrastructure of termite defence glands. In Hermann, H. R. (Ed.): Defensive Mechanisms in Social Insects, pp. 151-200. Praeger, New York.

Quennedey, A. 1998. Insect epidermal gland cells: ultrastructure and morphogenesis. In Harrison, F. W. and Locke, M. (Eds): Microscopic Anatomy of Invertebrates, Vol. 11A: Insecta, pp. 177-207. Wiley-Liss, New York.

Quennedey, A., Peppuy, A., Courrent, A., Robert, A., Everaerts, C. and Bordereau, C. 2004. Ultrastructure of posterior sternal glands of Macrotermes annandalei (Silvestri); new members of the sexual glandular set found in termites (Insecta). - Fournal of Morphology 262: 683-691.

Quennedey, A., Sillam-Dussès, D., Robert, A. and Bordereau, C. 2008. The fine structural organization of sternal glands of pseudergates and workers in termites (Isoptera): a comparative survey. Arthropod Structure and Development 37: 168-185.

Raina, A., Murphy, C., Florane, C., Williams, K., Yong Ihl, P. and Ingber, B. 2007. Structure of spermatheca, sperm dynamics, and associated bacteria in formosan subterranean termite (Isoptera: Rhinotermitidae). - Annals of the Entomological Society of America 100: 418-424.

Reinhard, J. and Kaib, M. 2001. Trail communication during foraging and recruitment in the subterranean termite Reticulitermes santonensis De Feytaud (Isoptera, Rhinotermitidae). - Fournal of Insect Behaviour 14: 157-171.

Reinhard, J., Hertel, H. and Kaib, M. 1997. Systematic search for food in the subterranean termite Reticulitermes santonensis De Feytaud (Isoptera, Rhinotermitidae). - Insectes Sociaux 44: 147-158.

Röhrig, A., Kirchner, W. H. and Leuthold, R. H. 1999. Vibrational alarm communication in the African fungus-growing termite genus Macrotermes (Isoptera, Termitidae). - Insectes Sociaux 46: 71-77.

Sbrenna, G. and Leis, M. 1983. Fine structure of the integumental glands of a termite soldier. - Tissue and Cell 15: 107-119.

Soares, H. X. and Costa-Leonardo, A. M. 2002. Survey of the leg exocrine glands in termites (Isoptera). - Revista Brasileira de Entomologia 46: 1-6.

Sobotnik, J., Weyda, F. and Hanus, R. 2003. Ultrastructure of epidermal glands in neotenic reproductives of the termite Prorhinotermes simplex (Isoptera: Rhinotermitidae). - Arthropod Structure and Development 32: 201-208.

Wall, M. 1969. Untersuchungen über die Tergaldrüse der Termite Kalotermes flavicollis (Fabr.) (Isoptera). Proceedings of the 6th International Congress of IUSSI, Berm, Switzerland, pp. 295-297. 